\title{
EVOLUÇÃO DA MALÁRIA POR Plasmodium berghei EM RATOS JOVENS ALIMENTADOS COM RAÇÕES COM DIFERENTES TEORES DE FERRO ${ }^{1}$
}

\section{Marly Augusto Cardoso ${ }^{2}$}

\section{RESUMO}

Evidências clínicas e experimentais sugerem que hospedeiros com deficiência de ferro são menos susceptíveis à malária grave e que a suplementação de ferro poderia agravar a infecção. No presente trabalho, ratos Wistar recém-desmamados foram alimentados com rações com diferentes teores de ferro: $20 \mathrm{mg} / \mathrm{kg}$ (grupo $1, n=24$ ), $50 \mathrm{mg} / \mathrm{kg}$ (grupo $2, n=$ 24) e $100 \mathrm{mg} / \mathrm{kg}$ (grupo $3, n=12$ ). No $16^{\circ}$ dia do experimento, quando os animais do grupo 1 estavam anêmicos (concentração média e desvio-padrão de hemoglobina sangüínea $[\mathrm{Hb}]$ : $8,1 \pm 1,0 \mathrm{~g} / 100 \mathrm{ml}$ ), os animais dos grupos 1 e 2 foram aleatoriamente subdivididos. Doze animais desses grupos passaram a receber a ração com suplementação de ferro, mantendo-se os demais sob a dieta anterior. Nove ratos de cada grupo foram inoculados com $10^{6}$ formas eritrocitárias de $P$. berghei (cepa ANKA), enquanto três animais de cada grupo foram mantidos como controles não-infectados. Todos os animais foram sacrificados 14 dias após a inoculação, quando níveis significantemente menores de $\mathrm{Hb}$, ferro sérico e saturação de transferrina foram observados nos animais do grupo $1 \mathrm{~A}$ em relação aos demais grupos. Entretanto, os picos das parasitemias foram semelhantes em todos os grupos. Esses resultados sugerem que o desenvolvimento de $P$. berghei em ratos não é suprimido pela deficiência de ferro. A suplementação de ferro antes e durante a infecção não aumentou as parasitemias. Além disso, a repleção de ferro durante a infecção produziu incrementos nos valores de $\mathrm{Hb}$ sangüinea e ferro sérico dos animais com anemia ferropriva.

\section{INTRODUÇÃO}

Em várias regiões tropicais com elevada prevalência de anemia ferropriva - África Ocidental, Sudeste Asiático e Amazônia -, observa-se também alta incidência de malária (Redd, Wirima \& Steketee, 1994; Binka et

1 Baseado em tese apresentada à Faculdade de Ciências Farmacêuticas da Universidade de São Paulo, sob a orientação da Profa. Marilene De Vuono Camargo Penteado, para a obtenção do título de Doutor. São Paulo, SP, Brasil, 1995.

2 Departamento de Nutrição, Faculdade de Saúde Pública, Universidade de São Paulo, São Paulo, Brasil.

Endereço para correspondência: Av. Dr. Arnaldo, 715 - CEP: 01246-904, São Paulo - SP, Brasil Tel.: (0xx11) 3066-7762. Fax: (0xx11) 3813 3526. E-mail: marlyac@hotmail.com

Recebido para publicação em: 1/6/2000. Revisto em 5/4/2001. Aceito em 10/4/2001. 
al., 1994). Esta situação tem suscitado alguns estudos sobre as relações entre a deficiência de ferro e a malária, dois fatores que se somam na produção da anemia. Na Amazônia brasileira, por exemplo, algumas investigações sugerem a malária e a deficiência de ferro como principais causas subjacentes à maior parte dos casos de anemia, de elevada prevalência em várias faixas etárias (Cardoso et al., 1992; Cardoso et al., 1994).

A malária é uma das doenças parasitárias mais prevalentes no mundo tropical. Estima-se a ocorrência anual de 210 milhões de casos, computando-se, somente na África, cerca de 2 milhões de óbitos anuais diretamente relacionados à malária, especialmente em crianças. Cerca de 1,7 bilhões de indivíduos habitam regiões de moderada à elevada transmissão, ou seja, mais de $30 \%$ da população mundial permanecem expostos à infecção, distribuídos em 99 países (WHO, 1992).

Na Amazônia brasileira são prevalentes duas espécies do parasita responsável pela malária humana - Plasmodium falciparum e $P$. vivax -, sendo raras as infecções por $P$. malariae. Na África Ocidental, entretanto, $P$. falciparum é a espécie predominante, identificada na maioria dos casos clínicos diagnosticados. Ocorrem também infecções por $P$. malariae e $P$. ovale, inexistindo virtualmente $P$. vivax (WHO, 1992).

Vários macro e micronutrientes são fundamentais para o desenvolvimento dos plasmódios. Observa-se, por exemplo, estreita dependência de meio rico em ferro para seu crescimento in vitro. O acréscimo de quelantes de ferro ao meio de cultura inibe o crescimento in vitro de $P$. falciparum, o parasita responsável pela forma mais grave de malária humana (Raventos-Suarez, Pollack \& Nagel, 1982; Iheanacho et al., 1990). Além disso, vem sendo descrita entre indivíduos com anemia ferropriva menor susceptibilidade às manifestações clínicas da malária, surgindo sintomas ao se corrigir esta deficiência. Há extenso debate sobre este possivel "efeito protetor" da deficiência de ferro em áreas endêmicas de malária, orientado para dirimir dúvidas sobre a necessidade de suplementação de ferro em populações de regiões de alta prevalência de anemia ferropriva (Oppenheimer, 1989b; Oppenheimer, 2001).

Há evidências de que o tratamento da deficiência de ferro, especialmente quando preparações com ferro parenteral são utilizadas, pode aumentar a susceptibilidade à malária. No entanto, além da via de administração do suplemento e de sua dose, podem interferir na interpretação dos resultados os seguintes fatores: o modelo epidemiológico utilizado, as características básicas da população de estudo (faixa etária, presença de imunidade clínica antimalárica, prevalência de deficiência de ferro e de outras deficiências nutricionais, níveis de assistência à saúde e educação), o tamanho amostral e a duração do estudo.

Como os efeitos adversos da suplementação de ferro na malária humana permanecem ainda polêmicos (Nakazawa et al., 1996; Oppenheimer, 
2001), resultados obtidos em estudos experimentais bem-controlados são fundamentais para o conhecimento das relações entre reservas orgânicas de ferro e infecção malárica, contribuindo para o delineamento de novos ensaios clínicos e epidemiológicos em áreas endêmicas de malária.

A evolução da infecção de $P$. berghei foi avaliada, neste trabalho, em um modelo experimental bem controlado de deficiência e suplementação de ferro em ratos recém-desmamados. Duas hipóteses foram testadas: (a) a de que a anemia ferropriva em ratos infectados com P. berghei teria "efeito protetor" contra a malária, resultando em parasitemias significantemente menores; (b) a de que a suplementação dietética de ferro, antes ou durante a infecção por $P$. berghei em ratos, levaria a parasitemias significantemente maiores.

\section{MATERIAIS E MÉTODOS}

\section{Animais e dietas}

Sessenta ratos machos albinos Wistar recém-desmamados (peso médio $44 \mathrm{~g}$ ), provenientes do biotério da FCF/USP, foram divididos inicialmente em três grupos (até o $15^{\circ}$ dia do experimento) e alimentados com rações à base de caseína normocalóricas e normoprotéicas, diferentes entre si quanto ao teor de ferro, com consumo alimentar ad libitum. A composição das rações, incluindo a formulação das misturas vitamínica e mineral, foi calculada segundo recomendações do Committee on Laboratory Animal Diets (1979).

Os animais foram mantidos em gaiolas metabólicas individuais de aço inoxidável. Semanalmente, os animais foram pesados, e amostras de sangue caudal foram colhidas para doseamento de $\mathrm{Hb}$.

\section{Procedimento experimental}

O tratamento dietético dos grupos experimentais é apresentado na Figura 1. No $16^{\circ}$ dia, os animais dos grupos 1 e 2 foram aleatoriamente subdivididos. Doze animais desses grupos passaram a receber a ração com suplementação de ferro, mantendo-se os demais sob a dieta anterior. Constituíram-se, portanto, cinco grupos de animais. Neste mesmo dia, nove ratos de cada grupo receberam inóculo intraperitonial de $10^{6}$ formas eritrocitárias de $P$. berghei (linhagem ANKA). Três ratos de cada grupo foram mantidos como controles não-infectados até o final do experimento. Amostras de sangue caudal foram obtidas para avaliação das parasitemias e para doseamento de $\mathrm{Hb}$.

No $30^{\circ}$ dia do experimento (14 dias após inoculação), todos os animais foram anestesiados e sacrificados por punção cardíaca. Amostras sangüíneas foram obtidas para dosagem de $\mathrm{Hb}$ (em tubos heparinizados) e 
soro (em tubos desmineralizados) para doseamento de ferro sérico, capacidade total de ligação de ferro e saturação de transferrina.

Análise da composição química das rações

A análise de composição química das rações foi realizada em triplicata segundo os métodos descritos pelo Instituto Adolfo Lutz (1985) e Association of Official Analytical Chemists (1984) para umidade, cinzas, nitrogênio e extrato etéreo. A determinação de ferro total foi realizada em espectrofotômetro de absorção atômica (Automatic Burner Control/ Perkin Elmer 5000) com lâmpada de leitura para ferro e calibrado com soluçãopadrão de ferro (Merck, Brasil), utilizando-se cerca de 2 gramas de amostras de ração previamente digeridas em bloco digestor a $350^{\circ} \mathrm{C}$ com ácido nítrico.

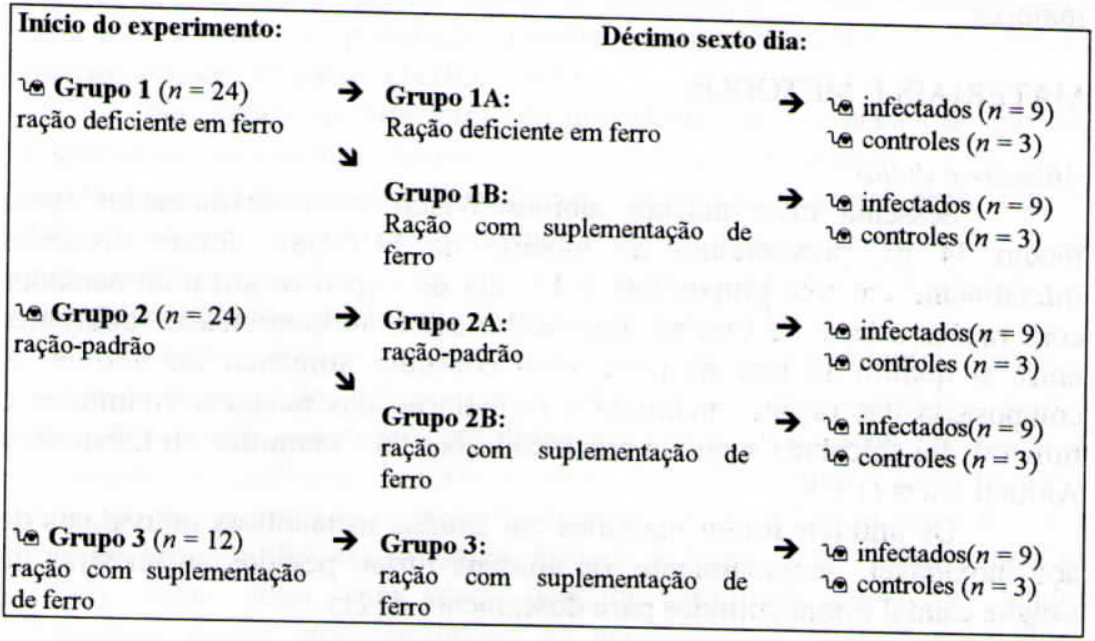

Figura 1. Tratamento dietético dos grupos experimentais.

Parâmetros hematológicos

- Doseamento de hemoglobina $(\mathrm{Hb})$, determinação de hematócrito (Ht) e volume corpuscular médio (VCM)

Para doseamento de $\mathrm{Hb}$ empregou-se o método da cianometahemoglobina, com solução de Drabkin modificada (van Assendelft, 1972). Um detergente não-iônico (Sterox $S E$, USA) foi adicionado à solução reagente para aumentar a hemólise e evitar turbidez por precipitação de proteinas plasmáticas. As absorbâncias foram medidas em espectrofotômetro (U-3410 Hitachi) a $540 \mathrm{~nm}$, com padrão de cianeto de potássio (Labtest, Brasil) para calibração.

Na determinação de Ht utilizaram-se microtubos centrifugados por cinco minutos segundo técnica rotineiramente utilizada (DeMaeyer et al., 1989). O VCM foi calculado dividindo-se o valor de hematócrito pelo 
número total de hemácias por litro de sangue, multiplicando-se o valor encontrado por 1.000 para expressar os resultados em femtolitro (fl) (Fairweather-Tait, 1993).

- Doseamento de ferro sérico (FS), capacidade total de ligação com ferro (CTLF) e saturação de transferrina (ST)

Utilizou-se ensaio automático (analisador automático COBAS MIRA-Roche) em $250 \mu \mathrm{l}$ de soro, empregando-se Ferrozine ${ }^{\circledR}$ como cromógeno a $560 \mathrm{~nm}$ para doseamento de FS total. Para a determinação da CTLF, adicionou-se às alíquotas de soro solução-padrão de ferro para saturação de transferrina e precipitação do ferro um excedente com carbonato de magnésio. A ST foi calculada dividindo-se o ferro sérico pela CTLF e multiplicando-se por 100 para expressar os resultados em percentagens.

\section{Avaliação da parasitemia}

Após o inóculo, a evolução das parasitemias dos animais foi avaliada por exame microscópico (1.000X) de esfregaços corados com corante de Giemsa, sendo as contagens (pelo menos 500 células) expressas em termos de percentagem de hemácias parasitadas (Bruce-Chwatt, 1980).

As percentagens total e parasitada de eritrócitos maduros e jovens (com policromatofilia) e eritroblastos em pelo menos 1.000 células foram estimadas em esfregaços periféricos obtidos no dia do sacrificio dos animais do segundo experimento. A classificação dos eritrócitos "jovens" considerou os vários estágios de diferenciação de células jovens com grande quantidade de retículo citoplasmático (Zuckerman, 1957).

\section{Análise estatística}

Os resultados são apresentados como média \pm desvios-padrão. Para algumas variáveis calcularam-se os respectivos intervalos da média com $95 \%$ de confiança (IC 95\%).

A prova não-paramétrica de Kruskal-Wallis foi utilizada para testar a hipótese de nulidade de que $k$ amostras independentes provêm de populações idênticas, ao nível de significância alfa $=0,05$. Quando rejeitada a hipótese de nulidade, utilizou-se a prova $U$ de Mann-Whitney na comparação entre dois grupos, ao nível de significância alfa $=0,05$. Os resultados obtidos para os animais-controle não foram incluídos na análise estatística devido ao seu tamanho amostral $(n=3)$.

\section{RESULTADOS}

A Tabela 1 apresenta a composição química média das rações à base de caseína. As rações foram normoprotéicas segundo recomendações para rações animais (Pellet \& Young, 1980). Em relação aos demais componentes, as rações diferiram somente em relação ao teor de ferro. As rações preparadas 
com mistura salina sem ferro apresentaram $0,002 \mathrm{~g}$ de ferro residual por 100 g (equivalente a $20 \mathrm{mg} / \mathrm{kg}$ ). A concentração desse mineral nas rações suplementadas correspondeu ao dobro do teor obtido nas rações do tipo "padrão".

Tabela 1. Composição química das rações (g/100g)

\begin{tabular}{l|c|c|c}
\hline \multirow{2}{*}{ Componente } & \multicolumn{3}{|c}{ Rações } \\
\cline { 2 - 4 } & Sem ferro & \multicolumn{1}{|c}{ Padrão } & \multicolumn{1}{c}{ Suplementação de ferro } \\
\hline Proteína & 17,400 & 17,000 & 17,200 \\
\hline Extrato etéreo & 5,400 & 5,400 & 5,500 \\
\hline Umidade & 8,500 & 8,800 & 8,700 \\
\hline Cinzas & 3,000 & 2,900 & 3,000 \\
\hline Ferro & 0,002 & 0,005 & 0,010 \\
\hline
\end{tabular}

A Tabela 2 mostra os pesos corporais e a concentração de $\mathrm{Hb}$ dos grupos de animais antes da inoculação de $P$. berghei $\left(15^{\circ}\right.$ dia do experimento). Não se observaram diferenças significantes nos pesos corporais (inicial e antes do inóculo) e no consumo de ração entre os grupos de animais. Entretanto, a concentração média de $\mathrm{Hb}$ dos animais do grupo 1 foi significantemente diferente da observada nos outros grupos.

Ao final do experimento, após infecção por $P$. berghei, os animais do grupo 1A apresentaram valores de peso corporal (média e desvio-padrão: $186,9 \pm 9,9 \mathrm{~g}$ ) estatisticamente menores em relação aos pesos dos animais dos grupos 1B $(209,4 \pm 21,6), 2 \mathrm{~A}(208,3 \pm 14,1), 2 \mathrm{~B}(212,9 \pm 20,5)$ e 3 $(209,3 \pm 19,1)$.

Tabela 2. Pesos corporais inicial e anterior à infecção (AI) e concentração de hemoglobina $(\mathrm{Hb})$ segundo grupos de animais antes da inoculação de P. berghei $\left(15^{\circ}\right.$ dia do experimento)

\begin{tabular}{c|c|c|c|c}
\hline $\begin{array}{c}\text { Grupos de } \\
\text { animais* }\end{array}$ & $n$ & $\begin{array}{c}\text { Peso inicial } \\
(\mathrm{g})\end{array}$ & $\begin{array}{c}\text { Peso AI } \\
(\mathrm{g})\end{array}$ & $\begin{array}{c}\mathrm{Hb} \\
(\mathrm{g} / 100 \mathrm{ml})\end{array}$ \\
\hline 1 & 24 & $44,1 \pm 3,4$ & $115,9 \pm 7,3$ & $8,1 \pm 1,0 * *$ \\
2 & 24 & $44,2 \pm 2,9$ & $120,7 \pm 7,8$ & $13,3 \pm 1,0$ \\
3 & 12 & $43,9 \pm 2,4$ & $121,2 \pm 9,8$ & $14,0 \pm 1,4$ \\
\hline
\end{tabular}

Média \pm desvio-padrão.

* Grupo 1 - animais alimentados com ração deficiente em ferro; grupo 2 - animais alimentados com ração padrão; e grupo 3 - animais alimentados com ração suplementada em ferro.

${ }^{* *} p<0,05$, grupo 1 versus 2 e 3 (prova $U$ de Mann-Whitney). 
Os valores médios da concentração de Hb, FS, CTLF e ST em cada grupo experimental, ao final do experimento (14 dias após inoculação de $P$. berghei), são apresentados na Tabela 3. Entre os animais infectados, o grupo 1A apresentou os menores valores de todos esses indicadores quando comparados os resultados relativos a cada grupo de animais. Entre os animais-controle observaram-se valores médios de concentração de $\mathrm{Hb}$ superiores aos valores médios dos animais infectados nos respectivos grupos experimentais, sendo que os animais-controle do grupo 1A continuavam anêmicos em relação aos demais grupos.

A Tabela 4 mostra as alterações na concentração de $\mathrm{Hb}$ dos grupos de animais infectados durante todo o experimento. Observa-se que no oitavo dia os animais do grupo 1 já apresentavam concentração média de $\mathrm{Hb}$ estatisticamente menor que os valores encontrados nos grupos 2 e 3 , com diferenciais maiores ainda no $15^{\circ}$ dia. Após a inoculação de $P$. berghei $\left(16^{\circ}\right.$ dia), todos os grupos de animais apresentaram queda acentuada na concentração média de $\mathrm{Hb}$, porém os animais do grupo $1 \mathrm{~A}$ apresentaram valor médio estatisticamente menor quando comparados aos demais grupos experimentais. Ao final do experimento, não houve diferenças estatisticamente significantes entre os valores de $\mathrm{Hb}$ dos grupos $1 \mathrm{~B}, 2 \mathrm{~A}, 2 \mathrm{~B}$ e 3 .

Tabela 3. Concentração de hemoglobina (Hb), ferro sérico (FS), capacidade total de ligação de ferro (CTLF) e saturação de transferrina (ST) nos grupos experimentais no $14^{\circ}$ dia de infecção por $P$. berghei

\begin{tabular}{|c|c|c|c|c|}
\hline $\begin{array}{l}\begin{array}{l}\text { Grupos de } \\
\text { animais** }\end{array} \\
\end{array}$ & $\begin{array}{c}\mathrm{Hb} \\
(\mathrm{g} / 100 \mathrm{ml})\end{array}$ & $\begin{array}{c}\text { FS } \\
(\mu \mathrm{mol} / 1)\end{array}$ & $\begin{array}{c}\text { CTLF } \\
(\mu \mathrm{mol} / 1)\end{array}$ & $\begin{array}{l}\text { ST } \\
(\%)\end{array}$ \\
\hline $\begin{array}{l}1 \mathrm{~A} \\
\text { infectados }\end{array}$ & $5,9 \pm 1,2 * *$ & $21,5 \pm 14,7^{* *}$ & $126,8 \pm 13,5 * *$ & $16,3 \pm 9,9 * *$ \\
\hline & $9,5 \pm 0,2$ & $10,3 \pm 2,7$ & $115,7 \pm 2,3$ & $8,7 \pm 2,4$ \\
\hline $\begin{array}{l}\text { infectados } \\
\text { controles }\end{array}$ & $\begin{array}{r}8,9 \pm 2,1 \\
12,9 \pm 0,7\end{array}$ & $\begin{array}{l}71,8 \pm 32,1 \\
40,7 \pm 6,7\end{array}$ & $\begin{array}{l}154,8 \pm 27,9 \\
135,0 \pm 2,5\end{array}$ & $\begin{array}{l}44,8 \pm 15,0 \\
30,0 \pm 4,4\end{array}$ \\
\hline & & & $1320 \pm 165$ & \\
\hline $\begin{array}{l}\text { infectados } \\
\text { controles } \\
2 \mathrm{~B} \text {. }\end{array}$ & $\begin{array}{r}7,5 \pm 1,5 \\
13,6 \pm 0,5\end{array}$ & $\begin{array}{l}48,6 \pm 21,9 \\
41,0 \pm 12,2\end{array}$ & $\begin{array}{l}132,0 \pm 16,5 \\
132,0 \pm 9,8\end{array}$ & $\begin{array}{l}35,8 \pm 14,1 \\
30,5 \pm 6,9\end{array}$ \\
\hline $\begin{array}{l}2 \mathrm{~B}: \\
\text { infectados } \\
\text { controles } \\
\text { 3: }\end{array}$ & $\begin{array}{r}8,9 \pm 2,4 \\
13,7 \pm 0,2\end{array}$ & $\begin{array}{l}70,4 \pm 33,9 \\
36,7 \pm 1,7\end{array}$ & $\begin{array}{l}154,5 \pm 26,1 \\
129,0 \pm 3,0\end{array}$ & $\begin{array}{l}43,9 \pm 14,7 \\
29,0 \pm 1,0\end{array}$ \\
\hline $\begin{array}{l}\text { infectados } \\
\text { controles }\end{array}$ & $\begin{array}{r}7,2 \pm 3,0 \\
13,7 \pm 0,4\end{array}$ & $\begin{array}{l}65,8 \pm 11,4 \\
29,0 \pm \quad 6,7\end{array}$ & $\begin{array}{l}145,6 \pm 12,9 \\
120,3 \pm 10,7\end{array}$ & $\begin{array}{l}45,1 \pm 7,5 \\
23,7 \pm 3,8\end{array}$ \\
\hline
\end{tabular}

Média \pm desvio-padrão.

* Animais infectados: $\mathrm{n}=9$; animais controles: $\mathrm{n}=3 \mathrm{em}$ cada grupo experimental.

${ }^{* *} p<0,05$, grupo $1 \mathrm{~A}$ versus todos os outros grupos (prova $U$ de Mann-Whitney). 
Tabela 4. Concentração de hemoglobina sangüinea $(\mathrm{g} / 100 \mathrm{ml})$ antes e após a inoculação de $P$. berghei

\begin{tabular}{|c|c|c|c|c|c|c|c|}
\hline \multirow{2}{*}{$\begin{array}{c}\text { Grupos de } \\
\text { animais }\end{array}$} & \multicolumn{4}{|c|}{ Antes da infecção } & \multicolumn{3}{|c|}{ Após a infecção } \\
\hline & $n$ & $7^{\circ}$ dia & $15^{\circ}$ dia & Grupos & $n$ & $21^{\circ}$ dia & $30^{\circ}$ dia \\
\hline 1 & 24 & $9,0 \pm 1,5^{*}$ & $8,1 \pm 0,9^{*}$ & $1 \mathrm{~A}$ & 9 & $7,5 \pm 1,5 *$ & $5,9 \pm 1,2 *$ \\
\hline & & & & IB & 9 & $8,3 \pm 1,8$ & $8,9 \pm 2,1$ \\
\hline 2 & 24 & $12,9 \pm 0,9$ & $13,3 \pm 0,9$ & $2 \mathrm{~A}$ & 9 & $8,6 \pm 1,8$ & $7,5 \pm 1,5$ \\
\hline & & & & $2 \mathrm{~B}$ & 9 & $8,9 \pm 1,8$ & $8,9 \pm 2,4$ \\
\hline 3 & 12 & $13,0 \pm 1,0$ & $14,0 \pm 1,4$ & 3 & 9 & $8,7 \pm 0,6$ & $7,2 \pm 3,0$ \\
\hline
\end{tabular}

Média \pm desvio-padrão.

* Estatisticamente diferente dos demais grupos de animais (prova $U$ de Mann-Whitney).

A evolução das parasitemias em cada grupo de animais até o $14^{\circ}$ dia após a inoculação de $P$. berghei é apresentada na Figura 2. Não houve diferenças significantes entre os grupos quando comparadas as parasitemias no mesmo dia da infecção (teste de Kruskal-Wallis com os seguintes valores de $p: 3^{\circ} \mathrm{dia}, p=0,49 ; 5^{\circ} \mathrm{dia}, p=0,93 ; 7^{\circ} \mathrm{dia}, p=0,91 ; 11^{\circ} \mathrm{dia}, p=0,90 ; 14^{\circ}$ dia, $p=0,42$ ). Analisando-se os valores médios dos picos das parasitemias por grupo de animais, não se observaram diferenças estatisticamente significantes entre os grupos experimentais (teste de Kruskal-Wallis $\operatorname{com} p=$ $0,919)$.

Além da avaliação das parasitemias totais nos grupos de animais, procedeu-se a um estudo morfológico da série vermelha em esfregaço de sangue periférico, ao final do experimento (14 dias após a inoculação de $P$. berghei). Avaliaram-se a distribuição percentual de cada tipo de célula e a proporção de células de cada tipo que se mostravam parasitadas. Cada estimativa foi baseada na análise de pelo menos 1.000 eritrócitos. Empregouse a seguinte classificação: hemácias maduras (M), hemácias jovens nucleadas com policromatofilia $(\mathrm{P})$ e eritroblastos $(\mathrm{E})$. A Tabela 5 apresenta a distribuição percentual e as parasitemias por tipo de eritrócito em cada grupo de animais. Quanto às parasitemias em cada tipo de célula, confirmou-se a preferência de $P$. berghei por eritrócitos jovens, uma característica essencial do modelo experimental empregado. Em todos os grupos experimentais, as parasitemias percentuais em eritrócitos com policromatofilia e em eritroblastos foram superiores às observadas em hemácias maduras. Esta preferência pareceu mais acentuada entre os animais do grupo 3, que apresentavam parasitemias percentuais em eritroblastos significantemente maiores que os demais grupos experimentais. 

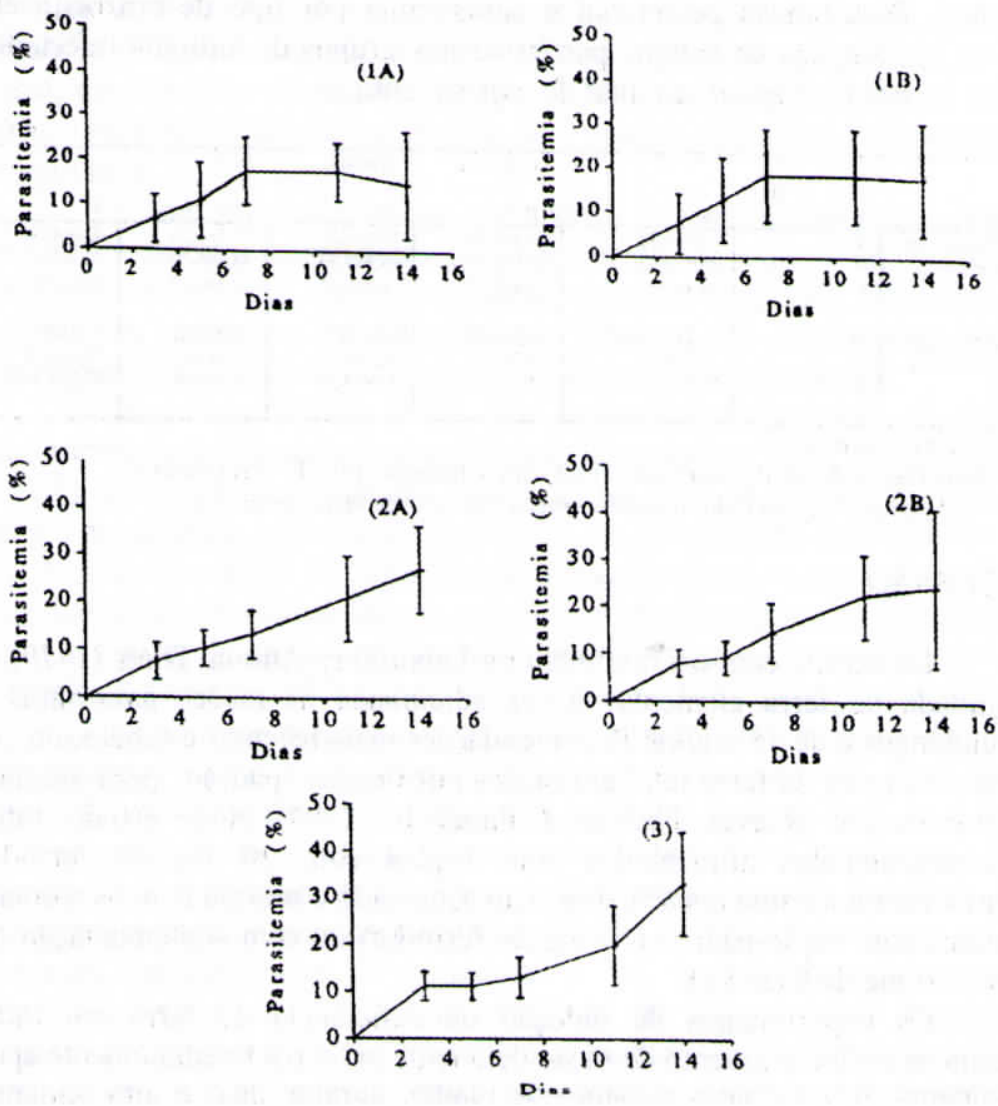

Figura 2. Parasitemia nos grupos experimentais: (1A) - animais alimentados com ração deficiente em ferro (20 mg de ferro/kg de ração); (1B) animais alimentados com ração deficiente em ferro que passaram a receber suplementação de ferro (110 mg de ferro/kg de ração) durante a infecção por $P$. berghei; (2A) - animais alimentados com ração-padrão (50 mg de ferro/kg de ração); (2B) - animais alimentados com ração-padrão que passaram a receber suplementação de ferro (110 $\mathrm{mg}$ de ferro/ $\mathrm{kg}$ de ração) durante a infecção; e (3) - animais alimentados com ração suplementada em ferro $(110 \mathrm{mg} / \mathrm{kg}$ de ração) desde o início do experimento. As barras verticais mostram os intervalos da média com $95 \%$ de confiança; $n=9$. Não houve diferenças estatisticamente significantes entre os grupos de animais (teste de Kruskal-Wallis). 
Tabela 5. Distribuição percentual e parasitemia por tipo de eritrócito em esfregaço de sangue periférico nos grupos de animais infectados por $P$. berghei, ao final do experimento

\begin{tabular}{|c|c|c|c|c|c|c|}
\hline Parâmetro & $\begin{array}{l}\text { Tipo de eri- } \\
\text { trócito* }\end{array}$ & $1 \mathrm{~A}$ & $\begin{array}{l}\text { Grupos de } \\
\text { IB }\end{array}$ & animais & $\begin{array}{l}(n=9) \\
2 \mathrm{~B} \\
\end{array}$ & 3 \\
\hline $\begin{array}{l}\text { Distribuição de } \\
\text { eritrócitos }(\%)\end{array}$ & $\begin{array}{l}\mathrm{M} \\
\mathrm{P} \\
\mathrm{E}\end{array}$ & $\begin{array}{r}57,9 \pm 0,52 \\
41,8 \pm 0,52 \\
0,3 \pm 0,05\end{array}$ & $\begin{array}{r}51,2 \pm 0,56 \\
47,9 \pm 0,56 \\
0,8 \pm 0,10\end{array}$ & $\begin{array}{r}50,5 \pm 0,52 \\
48,3 \pm 0,53 \\
1,2 \pm 0,12\end{array}$ & $\begin{array}{r}52,5 \pm 0,55 \\
44,2 \pm 0,55 \\
2,5 \pm 0,17\end{array}$ & $\begin{array}{l}42,8 \pm 0,50 \\
50,5 \pm 0,51 \\
6,6 \pm 0,25 * *\end{array}$ \\
\hline $\begin{array}{l}\text { Parasitemia por } \\
\text { tipo de eritróci- } \\
\text { to }(\%)\end{array}$ & $\begin{array}{l}\mathrm{M} \\
\mathrm{P} \\
\mathrm{E}\end{array}$ & $\begin{array}{c}1,2 \pm 0,153 \\
3,5 \pm 0,77 \\
33,3 \pm 9,6\end{array}$ & $\begin{array}{r}4,7 \pm 0,33 \\
31,7 \pm 0,75 \\
23,5 \pm 5,1\end{array}$ & $\begin{array}{l}3,5 \pm 0,27 \\
52,0 \pm 0,76 \\
42,8 \pm 4,68\end{array}$ & $\begin{array}{r}8,0 \pm 0,41 \\
43,8 \pm 0,82 \\
35,6 \pm 3,32\end{array}$ & $\begin{array}{l}3,7 \pm 0,29 \\
56,2 \pm 0,71 \\
57,1 \pm 1,97=*\end{array}$ \\
\hline
\end{tabular}

Média \pm desvio-padrão.

* $\mathrm{M}=$ hemácias maduras; $\mathrm{P}=$ hemácias jovens com policromatofilia; $\mathrm{E}=$ eritroblastos.

${ }^{* *} p<0,05$, grupo 3 versus todos os outros grupos (prova $U$ de Mann-Whitney).

\section{DISCUSSÃO}

De acordo com o Committee on Laboratory Animal Diets (1979), a quantidade de ferro elementar a ser adicionada às rações para ratos e camundongos é de $35 \mathrm{mg} / \mathrm{kg}$. Recomendações mais recentes estabelecem em média $45 \mathrm{mg} / \mathrm{kg}$ de ferro total em rações purificadas "padrão" para animais em crescimento (Reeves, Nielsen \& Fahey Jr., 1993). Neste estudo, ratos recém-desmamados alimentados com rações com $20 \mathrm{mg}$ de ferro/ $\mathrm{kg}$ desenvolveram anemia em sete dias, não ocorrendo o mesmo com os animais mantidos com ração-padrão ( $50 \mathrm{mg}$ de ferro $/ \mathrm{kg}$ ) ou com suplementação de ferro (100 $\mathrm{mg}$ de ferro/kg).

Os experimentos de indução de deficiência de ferro em ratos baseiam-se no fornecimento de ração deficiente em ferro imediatamente após o desmame (três a quatro semanas de idade), durante duas a oito semanas (Dallman et al., 1982; Wright \& Southon, 1990; Roodenburg et al., 1994). Este modelo apresenta a vantagem da utilização do período de maior necessidade de ferro dos animais. Por outro lado, observa-se algum comprometimento do crescimento em ratos alimentados com rações deficientes em ferro.

No presente estudo, os resultados dos indicadores bioquímicos de reservas de ferro (FS, CTLF e ST), analisados nos animais sacrificados antes da inoculação com $P$. berghei ( $15^{\circ}$ dia), confirmam o desenvolvimento de anemia ferropriva entre os animais mantidos com ração deficiente em ferro. Por outro lado, a suplementação oral com ferro durante 15 dias não alterou os valores desses parâmetros. Isto pode ser explicado pela regulação da absorção intestinal de ferro, que depende da comunicação entre as reservas de ferro corporal e a atividade eritropoiética (Cook, 1990). Sob condições fisiológicas adequadas, há um bloqueio da absorção pelas proteínas transportadoras de ferro da mucosa intestinal (Crosby, 1966). Em seres humanos (Idjradinata, 
Watkins \& Pollitt, 1994) e em ratos (Cook, Hershko \& Finch, 1973), a absorção de ferro é estreitamente relacionada às necessidades da medula óssea; em situações de reservas de ferro adequadas, a suplementação oral de ferro, dependendo da dose utilizada, não produz alterações em indicadores bioquímicos.

A análise estatística dos parâmetros hematológicos analisados não incluiu os animais sacrificados no primeiro dia do experimento (grupo 0) devido às diferenças fisiológicas entre animais de idades diferentes. No entanto, os resultados apresentados na Tabela 3 são consistentes com as alterações hematológicas esperadas para animais em crescimento.

Os níveis de $\mathrm{Hb}$ e $\mathrm{Ht}$ são ligeiramente menores em ratos e camundongos recém-nascidos, com hemácias grandes (VCM médio de 90 até $110 \mathrm{fl}$ ), acentuada policromasia e anisocitose. O VCM diminui rapidamente após o nascimento, alcançando o tamanho normal perto do desmame (50 a 60 fl). A concentração de $\mathrm{Hb}$ diminui após o nascimento a valores mínimos com dez dias de idade, quando ocorre aumento gradual na época do desmame, até atingir valores do animal adulto com aproximadamente trinta dias de idade (Ringler \& Dabich, 1979; Sanderson \& Phillips, 1981; Bannerman, 1983).

Estudos de deficiência de ferro em ratos têm demonstrado muitas semelhanças com o metabolismo de ferro em seres humanos. As etapas da evolução da deficiência de ferro são similares nessas duas espécies; a concentração de $\mathrm{Hb}$, a percentagem de volume sangüíneo em relação ao peso corporal e a quantidade de ferro por quilo de peso corporal são idênticos em ratos e em seres humanos (Dallman, 1982). As diferenças entre as duas espécies relacionam-se à gravidade e ao tempo necessário para o desenvolvimento da deficiência de ferro. O rato é mais imaturo ao nascimento, apresenta maior velocidade de crescimento pós-natal e tem vida útil relativamente curta de três anos. Este padrão do crescimento está associado a maiores necessidades de ferro (Cook, Hershko \& Finch, 1973).

Quanto à absorção de ferro, o rato, diferentemente dos seres humanos, utiliza muito mais o ferro não-heme do que o ferro heme da dieta. Há também diferenças na suscetibilidade à deficiência de ferro entre machos e fêmeas: as ratas apresentam maiores reservas de ferro e velocidade de crescimento muito menor quando comparadas aos machos e, por isso, são menos vulneráveis à deficiência de ferro da dieta (Dallman, 1982).

A diminuição da resposta eritropoiética à anemia tem sido observada em pacientes com malária (Abdalla et al., 1980) e no início da infecção por $P$. berghei em roedores (Villeval, Lew \& Metcalf, 1990). Camundongos com infecção letal por $P$. berghei apresentam menor celularidade e redução do número de eritroblastos na medula óssea femoral 24 horas após a infecção e antes de qualquer alteração de Ht. Com a evolução da infecção e 0 desenvolvimento da anemia, há o aumento da eritropoiese medular com alguma expansão do compartimento de células progenitoras eritróides (CFU- 
E, erythroid colony-forming cells), mas com resposta inadequada de reticulócitos (Maggio-Price, Brookoff \& Weiss, 1985).

A infecção malárica caracteriza-se pela maturação intracelular de trofozoitos a esquizontes, pela ruptura de eritrócitos e liberação de vários merozoítos que invadem outros eritrócitos. No $14^{\circ}$ dia da infecção por $P$. berghei em ratos, picos de parasitemias de 40 a $50 \%$ podem ser alcançados, dependendo do inóculo. A infeç̧ão então se resolve rapidamente com uma queda acentuada da parasitemia até o clareamento por volta do $20^{\circ}$ dia da infecção (Quinn \& Wyler, 1979). Ratos não desmamados podem desenvolver infecção letal em 16 dias com até $60 \%$ de eritrócitos parasitados (Thurston, 1953).

Em nosso estudo, utilizamos um modelo experimental de anemia ferropriva moderada, evitando-se com isso déficits maiores de crescimento.

As rações foram preparadas com este objetivo, sendo sua composição confirmada em nosso laboratório. O uso de rações comerciais, geralmente de composição quimica pouco conhecida, é uma das falhas mais comumente encontradas em estudos experimentais prévios sobre deficiência de ferro e malária. Rações comerciais podem apresentar concentração de ferro total em torno de $270 \mathrm{mg}$ de ferro/kg (Reeves, Nielsen \& Fahey Jr., 1993), valor superior ao encontrado em nossas rações com suplementação de ferro.

Além disso, as rações comerciais podem afetar o crescimento dos plasmódios devido à deficiência de outros nutrientes essenciais (Gilks et al., 1989). O ácido paraminobenzóico (PABA), por exemplo, parece ser necessário ao crescimento do parasita (Jacobs, 1964). P. berghei é praticamente incapaz de reduzir folato a deidrofolato e, conseqüentemente, depende de PABA exógeno para a síntese dos ácidos deidrofólico e tetraidrofólico (Ferone \& Hitchings, 1966). Ratos e camundongos infectados, alimentados com rações deficientes em PABA, apresentam redução do índice de mortalidade e aumento da sobrevida média em relação aos animais mantidos com ração com suplementação de PABA (Hawking, 1954; Keshavarz-Valian, Alger \& Boissonneault, 1985).

Algumas vitaminas antioxidantes podem modular os efeitos da infecção malárica por mecanismos que incluem a prevenção de lesão celular por espécies reativas de oxigênio (ROS, reactive oxygen species) e manutenção da função imune. $O$ desenvolvimento de plasmódios nos eritrócitos induz alterações fisiológicas e antigênicas nas células do hospedeiro que podem resultar em morte do parasita (Ginsburg \& Atamna, 1994). A resposta do hospedeiro à infecção malárica produz: ativação das células $\mathrm{T}$ por antígenos maláricos; ativação de fagócitos, principalmente macrófagos, pelas linfocinas derivadas das células T ativadas; e produção, pelos macrófagos, de citocinas e ROS que agrediriam os parasitas e tecidos do hospedeiro direta ou indiretamente (Hunt \& Stocker, 1990). O parasita 
responde ao estresse oxidativo alterando a estrutura e a função do eritrócito hospedeiro que, por outro lado, podem ser desfavoráveis para o desenvolvimento dos plasmódios (Golenser, Marva \& Chevion, 1991).

Neste experimento, a suplementação de ferro durante a infecção por $P$. berghei resultou em repleção hemoglobinica somente nos animais previamente deficientes em ferro (grupo lB), com aumento da concentração média de FS, CTLF e ST em relação aos resultados observados nos animais anêmicos sem ferro suplementar (grupo 1A). Uma das possíveis explicações para este fato relaciona-se à presença de receptores de transferrina nas membranas basal e lateral das células da mucosa intestinal e ao seu aumento na deficiência de ferro, facilitando a absorção através destas células (Huebers \& Finch, 1987; Flanagan, 1989). Essas alterações dos indicadores bioquímicos de reservas de ferro não agravaram a infecção por $P$. berghei uma vez que não foram observadas diferenças significantes entre as parasitemias dos grupos de animais.

Em situações de deficiência de ferro, há aumento da CTLF associado à mobilização de ferro dos compartimentos de reserva. As alterações de FS e da CTLF após suplemento oral de ferro devem ser interpretadas com cautela uma vez que o aumento do FS é influenciado por inúmeros fatores, como velocidade de absorção, eliminação de ferro sangüíneo, volume plasmático e concentração de transferrina (Laurell, 1954). No entanto, em nosso estudo, os altos níveis de FS, CTLF e ST observados nos animais dos grupos 1B, 2A, 2B e 3 podem ser decorrentes da hemólise; porém o aumento da concentração de $\mathrm{Hb}$ nos animais do grupo $\mathrm{lB}$ evidencia a utilização do ferro oral suplementar na vigência de infecção malárica em hospedeiros com anemia ferropriva.

Estudos anteriores sobre o efeito da infecção no metabolismo de ferro referem redução da atividade eritropoiética, evidenciada pelo aumento de PEL e pela diminuição da concentração média de $\mathrm{Hb}$ dos eritrócitos, menor concentração de FS e da ST (Hershko, Cook \& Finch, 1974). Na infecção malárica, as alterações de alguns parâmetros hematológicos podem diferir dependendo do estágio de evolução da doença. Na malária humana, a anemia hemolítica estimula a síntese de transferrina com o aumento da CTLF, facilitando a mobilização do ferro excedente liberado pela hemólise. Nesta fase, pode haver aumento do FS e da concentração sérica de transferrina (Aremu, 1989). Em ratos jovens, a infecção por $P$. berghei pode levar à anemia severa com aumento discreto da ST, sem alterações evidentes no FS e CTLF até o $12^{\circ}$ dia após a inoculação (Hershko \& Peto, 1988).

O ferro intracelular não está prontamente disponível para o crescimento de microrganismos. Proteínas de ligação, como a ferritina e a lactoferrina, impedem a captação do ferro em meios intracelulares (Weinberg, 1974). Entretanto, se houver maior disponibilidade de ferro para as células hospedeiras, poderá haver maior crescimento de microrganismos 
intracelulares (Weinberg, 1974). As alterações na homeostase do ferro associadas à infecção podem limitar a disponibilidade de ferro intracelular para microrganismos invasores pela redução do número de receptores de transferrina na superfície celular, comprometendo a disponibilidade do pool de ferro dos compartimentos de reserva independentemente do estado nutricional do hospedeiro (Hershko, 1993).

As alterações hematológicas observadas na malária experimental são acompanhadas de redução da atividade eritropoiética da medula óssea e aumento da eritropoiese extramedular (Asami et al., 1992). Durante a infecção por $P$. chabaudi AS, há redução da eritropoiese medular e aumento da atividade hemopoiética esplênica em camundongos resistentes, observando-se o aumento da incorporação esplênica de ${ }^{59} \mathrm{Fe}$ proporcional ao tamanho do órgão. Com o desenvolvimento da anemia, a celularidade e o número de células progenitoras (CFU-E) da medula óssea femoral diminuem progressivamente (Yap \& Stevenson, 1992). Alterações semelhantes são observadas com P. berghei (Maggio-Price, Brookoff \& Weiss, 1985), com maior produção de eritroblastos pelo baço (Villeval, Lew \& Metcalf, 1990).

A partir desses resultados e de experimentos prévios podemos discutir nossas hipóteses de estudo: a) a deficiência de ferro protegeria os animais contra a infecção experimental por $P$. berghei, resultando em parasitemias menores b) a suplementação dietética de ferro antes ou durante a infecção experimental por $P$. berghei em ratos produziria aumento significativo das parasitemias.

Para avaliar essas hipóteses, este estudo foi planejado de modo a reproduzir - em modelo experimental - situações freqüentes em áreas endêmicas de malária. Os grupos populacionais mais expostos à infecção correspondem geralmente àqueles em que a anemia ferropriva é mais prevalente. Portanto, ao contrair a infecção, alguns hospedeiros apresentam deficiência de ferro, enquanto os demais apresentam reservas orgânicas normais. Ao serem hospitalizados durante a infecção malárica, passam a receber a dieta hospitalar. Em certos casos, esta dieta pode ser particularmente rica em ferro, produzindo hiperferremia na vigência da infecção (Murray et al., 1975). O grupo suplementado com ferro antes da infecção representa um extremo para efeitos de comparação, mas pode também reproduzir a situação existente na população-alvo de programas de suplementação de ferro em áreas em que ocorre transmissão intensa de malária.

Em relação à hipótese (a), os possíveis mecanismos protetores são controversos. Segundo Luzzi et al. (1990), a invasão e o desenvolvimento in vitro de P. falciparum em hemácias microcíticas transcorrem de modo normal, de acordo com critérios morfológicos e metabólicos (incorporação de ${ }^{3} \mathrm{H}$-hipoxantina pelos parasitas). Em nosso experimento, não houve 
comprometimento do desenvolvimento de $P$. berghei em ratos com anemia ferropriva.

Quanto à hipótese (b), um dos possíveis mecanismos propostos seria o aumento da disponibilidade de células hospedeiras preferenciais - hemácias jovens - em decorrência da suplementação com ferro (Oppenheimer, 1989b). $\mathrm{O}$ estímulo da eritropoiese pela suplementação de ferro foi confirmado em nosso modelo experimental, particularmente entre os animais que receberam suplementação de ferro ao longo de todo o experimento. A preferência do parasita por hemácias jovens foi também confirmada em todos os grupos experimentais. Entretanto, não foi possível detectar qualquer relação entre a disponibilidade de hemácias jovens e eritroblastos na periferia e o percentual de eritrócitos (jovens + maduros) parasitados. Portanto, a suplementação de ferro, tanto antes quanto durante a infecção - e independentemente das reservas de ferro prévias do hospedeiro -, não afetou o curso da infecção experimental por $P$. berghei em ratos jovens.

A resposta eritropoiética mais intensa observada entre os animais suplementados com ferro antes e durante a infecção parece relacionada à duração da suplementação e ao aproveitamento biológico do ferro administrado por via oral durante a infecção malárica. Somente nestes animais, que vinham há mais tempo sendo submetidos à suplementação com ferro, observou-se maior percentagem de eritroblastos em sangue periférico.

Os efeitos da suplementação de ferro na resposta imunológica e eritropoiética de hospedeiros com infecção malárica são particularmente importantes para a prática clínica em áreas endêmicas de malária com alta prevalência de anemia ferropriva. No entanto, serão necessários estudos experimentais e clínicos posteriores para o esclarecimento da atividade eritropoiética esplênica e medular em hospedeiros com diferentes regimes de suplementação oral de ferro.

\section{AGRADECIMENTOS}

À Fundação de Amparo à Pesquisa do Estado de São Paulo (Fapesp) e ao Conselho Nacional de Desenvolvimento Científico e Tecnológico ( $\mathrm{CNPq})$, pela subvenção.

\section{SUMMARY}

Effect of different iron regimens on the course of Plasmodium berghei malaria in young rats.

Clinical and experimental evidence suggests that iron-deficient hosts are less susceptible to severe malaria and that iron supplementation aggravates infection. In the present study, weanling Wistar rats were fed on standard diets with different iron concentrations: $20 \mathrm{mg} / \mathrm{kg}$ (group $1, n=24$ ), 50 $\mathrm{mg} / \mathrm{kg}$ (group 2, $n=24$ ) and $100 \mathrm{mg} / \mathrm{kg}$ (group 3, $n=12$ ). After the 15-day regimen, rats from group 1 were anaemic (mean hemoglobin $[\mathrm{Hb}]$ and 
standard deviation: $8.1 \pm 1.0 \mathrm{~g} / 100 \mathrm{ml}$ ). For the next step, 12 rats from group 1 (thereafter group 1B) and 12 from group 2 (thereafter group 2B) were given the same iron-supplemented diet used in group 3, while the remaining animals (groups 1A, 2A and 3) were maintained on the original diets. At this occasion, 9 animals from each group were inoculated intraperitoneally with $10^{6}$ erithrocytic parasites ( $P$. berghei ANKA strain), whereas 3 animals from each group remained as noninfected controls. All animals were sacrificed 14 days after inoculation, when significantly lower levels of $\mathrm{Hb}$, serum iron and transferrin saturation were found only in animals from group $1 \mathrm{~A}$, when compared with other groups. However, percent peak parasitaemias were similar in all groups. These data indicate that the development of $P$. berghei is neither suppressed by iron deficiency nor enhanced by iron supplementation in the used model. Furthermore, iron repletion during infection produced a noticeable improvement of haematological parameters in previously iron-deficient animals.

\section{REFERÊNCIAS}

1. Abdalla SH, Weatherall DJ, Wickramasinghe $\mathrm{SN}$, Hughes $\mathrm{M}$. The anaemia of $P$. falciparum malaria. B J Haematol 46:171-183, 1980.

2. Aremu $\mathrm{CY}$. Changes in serum transferrin and iron concentrations in humans suffering from malaria with parasitaemia. Ann Trop Med Parasitol 83: 517-520, 1989

3. Asami M, Abe T, Owhashi M, Nawa Y. Appearence of adherent cells suppressive to erythropoiesis during an early stage of Plasmodium berghei infection in mice. Southeast Asian J Trop Med Public Health 23, 184-188, 1992.

4. Association Of Official Analytical Chemists. Official methods of analysis. 14.ed. Arlington, 1984.

5. Bannerman, RM Hematology. In: Foster, HL Small, JD Fox, JG eds. The mouse in biomedical research. New York: Academic Press, 1983. 3: 293-312.

6. Binka FN, Morris SS, Ross DA, Arthur P, Aryeetey ME. Patterns of malaria morbidity and mortality in children in northern Ghana. Trans R Soc Trop Med Hyg 88: 381-385, 1994.

7. Bruce-Chwatt, LJ Essential malariology. London: William Heinemann, 1980.

8. Cardoso MA, Ferreira UM, Camargo LMA, Szarfarc SC. Anemia em população de área endêmica de malária, Rondônia (Brasil). Rev. Saúde Pública, 26: 161-166, 1992.

9. Cardoso MA, Ferreira UM, Camargo LMA, Szarfarc SC. Anaemia, iron deficiency and malaria in a rural community in Brazilian Amazon. Eur J Clin Nutr 48: 326-332, 1994.

10. Committee on Laboratory Animal Diets/ Institute of Laboratory Animal Resources/ National Research Council. Controls of diets in laboratory animal experimentation. Nutr Abstr Rev B,49: 413-419, 1979 (Report).

11. Cook JD. Adaptation in iron metabolism. Am J Clin Nutr 51: p 301-308, 1990.

12. Cook JD, Herchko C, Finch CA. Storage iron kinetics. V. Iron exchange in the rat. $\mathrm{Br} J$ Haematol., 25:695-706, 1973.

13. Crosby WH. Mucosal block: an evaluation of concepts relating to control of iron absorption. Semin. Hematol.,3: 299-313, 1966.

14. Dallman PR, Refino C, Yland MJ. Sequence of development of iron deficiency in the rat. Am. J Clin Nutr, 35:671-677, 1982.

15. DeMaeyer EM, Dallman P, Gurney JM, Hallberg L, Sood SK, Srikantia SG. Preventing and controlling iron deficiency anaemia through primary health care. Geneve: World Health Organization, 1989.34-42. 
16. Fairweather-Tait, S. Iron. Int J Vitam Nutr Res 63:296-301, 1993.

17. Ferone R, Hitchings GH. Folate cofactor biosynthesis by Plasmodium berghei. Comparison of folate and dihydrofolate as substrates. J Protozool 13:504-508, 1966.

18. Flanagan PR. Mechanisms and regulation of intestinal uptake and transfer of iron. Acta Paediatr Scand Suppl 361: 21-30, 1989.

19. Gilks CF, Jarra W, Harvey-Wood K, McLean AS, Schetters T. Host diet in experimental rodent malaria: a variable which can compromise experimental design and interpretation. Parasitology 98: 175-177, 1989.

20. Ginsburg H, Atamna H. The redox status of malaria-infected erythrocytes: an overview with an emphasis on unresolved problems. Parasite 1:5-13, 1994.

21. Golenser J, Marva E, Chevion M. The survival of Plasmodium under oxidant stress. Parasitol Today 7: 142-146, 1991.

22. Hawking F, Milk. P-aminobenzoate, and malaria of rats and monkeys. Br Med J 2: 425 $429,1954$.

23. Hershko C. Iron, infection and immune function. Proc Nutr Soc 52:165-174, 1993.

24. Hershko C, Cook JD, Finch CA. Storage iron kinetics. VI. The effect of inflammation on iron exchange in the rat. Br J Haematol 28:67-75, 1974.

25. Huebers HÁ, Finch CA. The physiology of transferrin and transferrin receptors. Physiol Rev 67:520-582, 1987.

26. Hunt NH, Stocker R. Oxidative stress and the redox status of malaria-infected erythrocytes. Blood Cells 16:499-526, 1990.

27. Iheanacho EN, Samuni A, Avramovici-Grisaru S, Sarel S, Spira. DT Inhibition of Plasmodium falciparum growth by a synthetic iron chelator. Trans $R$ Soc Trop Med Hyg 84:213-216, 1990.

28. Instituto Adolfo Lutz. Normas analiticas do Instituto Adolfo Lutz. 3.ed. São Paulo, 1985. 1.

29. Jacobs RL. Role of P-aminobenzoic acid in Plasmodium berghei infection in the mouse. Exp Parasitol 15:213-225, 1964.

30. Keshavarz-Valian H, Alger NE, Boissonneault GA. Effects of p-aminobenzoic acid, methionine, threonine and protein levels on susceptibility of mice to Plasmodium berghei $J$ Nutr 115:1613-1620, 1985.

31. Laurell CB. Plasma iron and the transport of iron in the organism. Pharmacol Rev 4:371395, 1954.

32. Luzzi GA, Torii M, Aikawa M, Pasvol G. Unrestricted growth of Plasmodium falciparum in microcytic erythrocytes in iron deficiency and thalassaemia. Br J Haematol 74: 519-524, 1990.

33. Maggio-Price L, Brookoff D, Weiss L. Changes in hematopoietic stem cells in bone marrow of mice with Plasmodium berghei malaria. Blood 66:1080-1085, 1985.

34. Murray MJ, Murray CJ, Murray AB, Murray MB. Refeeding-malaria and hyperferraemia. Lancet, 1:653-654, 1975.

35. Nakazawa M, Ohtsuka R, Kawabe $T$, Hongo $T$, Inaoka $T$, Akimichi $T$, Suzuki $T$. Iron nutrition and anaemia in a malaria-endemic environment: haematological investigation of the Gidra-speaking population in Iowland Papua New Guinea. Br J Nutr 76:333-346, 1996.

36. Oppenheimeir SJ. Iron and infection: the clinical evidence. Acta Paediatr Scand Suppl 361:53-62, 1989a.

37. Oppenheimer SJ. Iron and its relation to immunity and infectious disease. $J$ Nutr 131:616S35S, 2001.

38. Oppenheimer SJ. Iron and malaria. Parasitol Today 5:77-79, 1989b.

39. Pan American Health Organization (PAHO). Status of malaria programs in the Americas. XL Report. Documento não-publicado. Washington: PAHO, 1992.

40. Pellet PL, Young VR. Nutritional evaluation of protein foods. Tokyo: United Nations University, 1980.

41. Quinn TC, Wyler DJ. Resolution of acute malaria (Plasmodium berghei in the rat): reversibility and spleen dependence. Am J Trop Med Hyg 29: 1-4, 1980. 
42. Raventos-Suarez C, Pollack S, Nagel RL Plasmodium falciparum: inhibition of in vitro growth by desferrioxamine. Am J Trop Med Hyg 31: 919-922, 1982.

43. Redd SC, Wirima JJ, Steketee RW. Risk factors for anemia in young children in rural malawi. Am J Trop Med Hyg 51: 170-174, 1994.

44. Reeves PG, Nielsen FH, Fahey Jr GC. AIN-93 Purified diets for laboratory rodents: final report of the American Institute of Nutrition ad hoc writing committee on the reformulation of the AIN-76A rodent diet. $J$ Nutr 123P: 1939-1951, 1993.

45. Ringler DH, Dabich L. Hematology and clinical biochemistry. In: Baker, H.J., Lindsey, J.R., Weisbroth, S.H., eds. The laboratory rat New York: Academic Press, 1979.1 105121.

46. Roodenburg AJ, West CE, Yu S, Beynen A. Comparison between time-dependent changes in iron metabolism of rats as induced by marginal deficiency of either vitamin A or iron. $\mathrm{Br}$ J Nutr 71:687-699, 1994.

47. Sanderson JH, Phillips CE. An atlas of laboratory animal haematology. Oxford: Clarendon Press, 1981.38-41.

48. Thurston, JP. Parasitological reviews: Plasmodium berghei Exp Parasitol, 2:311-332, 1953.

49. van Assendelft OW. Measurement of hemoglobin. In: Izak G, Lewis SM, eds. Modern concepts in hematology. New York: Academic Press, 1972. 14-24.

50. Villeval J-L, Lew A, Metcalf D. Changes in hemopoietic and regulator levels in mice during fatal or nonfatal malarial infections. I. Erythropoietic populations. Exp Parasitol 71:364-374, 1990.

51. Weinberg ED. Iron and susceptibility to infectious disease. Science, 184,952-956, 1974.

52. World Health Organization (WHO). World malaria situation 1990. World Health Sta $Q$ 45:257-266, 1992.

53. Wright AJA, Southon S. The effectiveness of various iron-supplementation regimens in improving the Fe status of anaemic rats. Br J Nutr 63:579-585, 1990.

54. Yap GS, Stevenson MM. Plasmodium chabaudi AS: erythropoietic responses during infection in resistant and susceptible mice. Exp Parasitol 75: 340-352, 1992.

55. Zuckerman A. Blood loss and replacement in plasmodial infections. I. Plasmodium berghei in untreated rats of varying age and in adult rats with erythropoietic mechanisms manipulated before inoculation. J Infect Dis 100:172-206, 1957. 